13 Petrie JC, O'Brien ET, Littler WA, Swiet MD, Dillon MJ, Padfield PL. Recommendations on blood pressure measurements. 2nd ed. London: BMJ Publishing Group, 1990.

14 Prineas R, Crow R, Blackburn H. The Minnesota code manual of electrocardiographic findings. London: John Wright, 1982.

15 Rose G, Blackburn A, Gillum R, Prineas R. Cardiovascular survey methods. 2nd ed. Geneva: World Health Organisation, 1982.

16 Bennett N, Dodd T, Flatley J, Freeth S, Boiling K, for the Office of Population Censuses and Surveys. Health survey for England 1993. London: HMSO, 1995

17 Department of Health. Health survey for England '96. London: Stationery Office, 1998.

18 NHS Centre for Reviews and Dissemination. Cholesterol and coronary heart disease: screening and treatment. Effective Health Care 1998; No 4.

19 Raine R, Streetly A, Davis AM. Variation in local policies and guidelines for cholesterol management: national survey. BMJ 1996;313:1368-9.

20 Thomson R, McElroy H, Sudlow M. Guidelines on anticoagulant treatment in atrial fibrillation in Great Britain: variation in content and implications for treatment. BMJ 1998;316:509-13.

21 Fahey TP, Peters TJ. What constitutes controlled hypertension? Patient based comparison of hypertension guidelines. BMJ 1996;313:93-6.
22 Pedersen TR, Kjekshus J, Berg K, Haghfelt T, Faergeman O, Thorgeirsson $\mathrm{G}$, et al. Randomised trial of cholesterol lowering in 4444 patients with coronary heart disease: the Scandinavian simvastatin survival study (4S). Lancet 1994;344:1383-9.

23 Sacks FM, Pfeffer MA, Moye LA, Rouleau JL, Rutherford JD, Cole TG, et al. The effect of pravastatin on coronary events after myocardial infarction in patients with average cholesterol levels. $N$ Engl J Med infarction in pation:

24 Shepherd J, Cobbe SM, Ford I, Isles CG, Lorimer AR, Macfarlane PW, et al. Prevention of coronary heart disease with pravastatin in men with hypercholesterolemia. N Engl J Med 1995;333:1301-7.

25 Freemantle N, Barbour R, Johnson R, Marchment M, Kennedy A. The use of statins: a case of misleading priorities? National guidance that does not link costs and benefits is worthless. BMJ 1997;315:826-8.

26 Grimshaw J, Russell I. Achieving health gain through clinical guidelines I: Developing scientifically valid guidelines. Qual Health Care 1993;2:243-8.

27 Eccles M, Clapp Z, Grimshaw J, Adams PC, Higgins B, Purves I, et al. North of England evidence based guidelines development project: methods of guideline development. BMJ 1996;312:760-1.

(Accepted 6 July 1998)

\title{
From trial data to practical knowledge: qualitative study of how general practitioners have accessed and used evidence about statin drugs in their management of hypercholesterolaemia
}

\author{
Karen Fairhurst, Guro Huby
}

Editorial by Fahey and $p p 1120,1125$, 1134

Department of Community Health Sciences (General

Practice), University of Edinburgh, Levinson House, Edinburgh EH8 9DX

Karen Fairhurst, lecturer

Guro Huby, research associate

Correspondence to: Dr Fairhurst Karen.Fairhurst@ ed.ac.uk

BMJ 1998;317:1130-4

\begin{abstract}
Objectives To explore how general practitioners have accessed and evaluated evidence from trials on the use of statin lipid lowering drugs and incorporated this evidence into their practice. To draw out the practical implications of this study for strategies to integrate clinical evidence into general medical practice.
\end{abstract}

Design Qualitative analysis of semistructured interviews.

Setting General practices in Lothian.

Subjects 24 general practitioners selected to obtain a heterogeneous sample.

Results Respondents were generally aware of the evidence relating to the use of statins in secondary prevention of coronary heart disease, but they were less clear about the evidence in primary prevention. The benefits of statins in secondary prevention were clearer to them and the social and economic issues less complex than was the case for use in primary prevention. Respondents rarely said they appraised the methods and content of trials, rather they judged the trustworthiness of the source of trial evidence and interpreted it within the context of the economic and social factors which impinge on their practice.

Moreover, trial data become relevant for routine practice only when underpinned by a consensus on these issues.

Conclusion Strategies to promote incorporation of evidence from clinical trials into everyday practice are likely to be effective if they tap into and build on the process of local consensus building. Strategies such as teaching critical appraisal skills and guideline development may have little effect if they are separated from this process.

\section{Introduction}

Use of evidence from clinical trials to underpin routine practice is seen as a key part of achieving a cost effective health service that offers consistent high quality care. ${ }^{12}$ Evidence based medicine requires doctors to appraise clinical trials critically to determine the best way of managing a patient's clinical problem. ${ }^{3}$ Evidence based medicine is seen as particularly problematic in general practice, where clinical problems are presented in complex social and psychological contexts. ${ }^{4}$ Although support for the principle of evidence based medicine has been identified among general practitioners, ${ }^{5}$ recognised barriers exist to its implementation. Studies that have explored how general practitioners access evidence and translate this into practice suggest that strategies based on critical appraisal might fail because they are based on unrealistic models of how "evidence" is accessed and evaluated. ${ }^{6-8}$

We present findings from a study in which general practitioners reflected on how they access and incorporate into their practice evidence on management of lipid disorders. We chose this subject as data from recent randomised controlled trials, in particular from the Scandinavian simvastatin survival study $(4 S)^{9}$ and the West of Scotland coronary prevention study (WOSCOPS), ${ }^{10}$ have a high profile and direct relevance to primary care, and local prescribing data suggest wide variation between practices in levels of prescribing of statin drugs. We compared general practitioners' accounts of their current practice with results from the two studies. The Scandinavian study produced evidence of around a 30\% reduction in risk of myocardial infarction and death in patients with known ischaemic heart disease whose total serum cholesterol 
concentration was lowered to $<5.2 \mathrm{mmol} / \mathrm{l}$ with titrated doses of simvastatin. The Scottish study showed a similar 30\% reduction in risk of myocardial infarction and death in middle aged men with moderately raised total serum cholesterol concentrations $(>6.5 \mathrm{mmol} / \mathrm{l})$ without pre-existing coronary heart disease whose serum cholesterol concentration was reduced by a mean of $20 \%$ with pravastatin. The cost implications of this evidence are recognised ${ }^{112}$ and whereas the use of statin drugs in secondary prevention is encouraged, their use in primary prevention is not deemed cost effective and is discouraged both in national guidelines ${ }^{13}$ and through prescribing advisers in the local setting for this study.

From this material a distinction emerged between "trial data" such as findings from the Scandinavian and Scottish studies on the one hand and "practical knowledge" as practitioners' understanding, acceptance, and use of these "trial data" in practice on the other hand. This differentiation is central to the following presentation of our findings.

We had two aims: firstly, to explore patterns in general practitioners' awareness of the trial results and their application in practice, and, secondly, to draw out possible implications of our findings for appropriate strategies to integrate clinical evidence into general medical practice.

\section{Subjects and methods}

The main part of the study involved qualitative interviews with general practitioners. We also interviewed relevant hospital specialists to obtain a local secondary care perspective and health board staff to provide insight into the local context in respect of the promotion of clinical effectiveness in Lothian.

\section{Sample selection}

To generate a sample representing variation in prescribing patterns for statin drugs and sociodemographic characteristics of practice populations all general practices in Lothian were ranked according to the defined daily dose (DDD) ${ }^{14}$ of statin lipid lowering drugs prescribed per patient and then divided into high, medium, and low prescribers. High prescribing practices were defined as those in the highest quarter for defined daily dose per patient prescribed $(>1.4)$, medium prescribing practices as those in the second and third quarter (0.5-1.4), and low prescribing practices as those in the lowest quarter $(<0.5)$. Practices were also categorised according to the proportion of their patients for whom deprivation payments were received and the proportion of their patients aged 65 and over. High, medium, and low deprivation practices received deprivation payments for, respectively, $11 \%$ or more, 5 - $10 \%$, or less than $5 \%$ of their patients. For age practices were categorised, respectively, as having $9 \%$ or more, $7-8 \%$, or less than $7 \%$ of their patients aged 65 and over.

These divisions generated 27 categories of general practice. One general practitioner was selected from each category of practice to include general practitioners who differed in sex, ethnic group, and seniority and worked in different sized partnerships. Of the original sample of 27 doctors, 11 declined to participate. Eight of these were replaced by doctors of similar characteristics.

\section{Interviews}

The interview schedule asked doctors to describe their current practice in relation to management of lipid disorders and prescription of lipid lowering drugs and any recent change that had occurred in their own clinical behaviour or practice policy. Doctors were asked to reflect on how and why change had happened and factors influencing it. As a comparison they were asked to identify another part of their clinical practice in which there had been recent change and to reflect on the reasons for that change.

The interviews were semistructured to allow interviewees to raise and discuss issues around the application of trial data relevant to themselves rather than reflecting the prevailing debate about evidence based medicine. They were conducted by the authors and tape recorded. The tapes were transcribed verbatim and the transcripts examined independently by both of us. We extracted the ways in which trial evidence was incorporated into everyday practice and the factors and issues impacting on this process; identified emerging themes and categories; and derived a set of codes. We met regularly to discuss and modify our coding framework, which was then applied across all interviews.

\section{Results}

Twenty four general practitioners eventually took part in the study, no more than one from each category of practice. Eleven were women, three were from ethnic minorities, and three were senior partners. The average number of partners in each practice was 4.4, one doctor practised single handedly, and the three largest practices had eight partners each.

\section{What general practitioners said they did}

Secondary prevention - Respondents did not always explicitly differentiate between primary and secondary prevention of coronary heart disease in the way that clinical trials do. They talked about assessing risk from hypercholesterolaemia in individual patients, testing those at highest perceived risk, and treating those found to have raised cholesterol concentrations. All our interviewees were broadly aware of the evidence derived from the Scandinavian study about the benefits of treating hypercholesterolaemia in people with coronary heart disease who were universally regarded as being at highest risk. The two respondents who questioned this approach did so on the grounds that it marginalises the contributions of socioeconomic and lifestyle factors in the aetiology and management of coronary heart disease. The specific findings of the Scandinavian study, however, were less well known. For example, a target concentration for serum cholesterol in patients with coronary heart disease was cited by only four respondents, all of whom cited the correct concentration of $5.2 \mathrm{mmol} / \mathrm{l}$.

Primary prevention-Our interviewees described their uncertainty in the management of lipid disorders in patients without pre-existing coronary heart disease. All but two accepted that lowering serum cholesterol concentration in asymptomatic patients with raised 
concentrations was likely to reduce cardiac events, a belief supported by the evidence from the Scottish study. They were ambivalent, however, about whether and how they should apply this in practice. No one was pursuing the policy of universal testing and treatment which could be extrapolated from the results of the Scottish study. Seventeen respondents, however, described treating hypercholesterolaemia in patients whom they perceived from assessment of risk factors to be at high risk of developing coronary heart disease. The exact risk factors quoted varied among the respondents. Procedures for identifying which high risk patients to test and subsequent treatment also varied. Descriptions of management had no consistent relation with trial evidence. Most interviewees said they would use a statin drug to lower serum cholesterol concentration after variable periods of dietary advice, but a substantial number were using other classes of lipid lowering drugs.

\section{Which studies were cited}

When we asked them about their understanding of the sources of evidence on management of hyperlipidaemia respondents most often referred to the Scandinavian and Scottish studies. Only five respondents said they had read the original Scandinavian article and two said they had read the Scottish article. The study by Sacks et al (CARE) $)^{15}$ was mentioned, but only one of the respondents knew of its findings. More typically knowledge about the studies had, in the words of one respondent, "trickled down" to them through various channels. The Scandinavian study was mentioned more often and had a bigger and clearer profile than the others in terms of changing practice. Several respondents clearly remembered attending postgraduate meetings where the findings of Scandinavian study and their implications were presented. Four respondents cited the methods and sample size of the study as reasons to trust the findings.

In comparison, although similar levels of awareness of the Scottish study were apparent, our respondents were less likely to recall specific situations in which the trial had been discussed. Also the social and economic implications of primary prevention of coronary heart disease were less acceptable within the context and constraints of current practice and less clear cut than was the case for secondary prevention. Reservations about the cost, both in terms of drug costs and workload, of implementing the Scottish findings were uppermost. Many respondents cited clear signals from the local health authority to curb the cost of lipid lowering drugs in prevention of coronary heart disease. Fears about "medicalising" healthy patients, however, were also prevalent. The trial evidence was seen by our respondents as peripheral for a condition for which they believed modification of lifestyle was more fundamental:

“... it's the management of the ills of society that's going to solve medical problems ... maybe getting people to stop smoking, completely banning it, would be far more important than all this RCT stuff" (general practitioner 4).

The evidence concerning the role of lipid lowering drugs in secondary prevention of coronary heart disease had "filtered down" to our respondents, and they were able to articulate how the evidence had impacted on their practice. Primary prevention remained firmly part of a "clinically grey area"16 for our respondents. Crucial to understanding the practical importance of this finding is the analytical distinction between "trial data" knowledge and "practical knowledge" and the route from one to the other.

\section{Trust: sources of information and their authority}

Our respondents' accounts of sources of information about hypercholesterolaemia and lipid lowering drugs confirm findings of previous studies. ${ }^{7817}$ Generally personal contact was valued above written sources. Information was commonly gathered from postgraduate meetings, in particular those addressed by consultant colleagues, from personal contact with hospital consultants, from written hospital correspondence, and from colleagues in general practice, specifically those perceived to have a special interest. Both lay and medical media were commonly reported sources. Respondents admitted to lacking both the time and skills to appraise the content of scientific papers critically and said they relied on editorial comment in, for example, the $B M J$, and on précis and summaries of original studies in Update and Monitor. Review publications and national and local guidelines were also mentioned, but their impact was diluted by the large quantity of guidelines produced by various bodies and their perceived length and complexity. In the local context health board prescribing advisers were seen as providers of information. Sometimes, reluctantly, pharmaceutical companies, through their representatives, were recognised as providing information.

These sources were not all of equal importance but were ranked according to trust. Commonly our respondents talked about assessing the sources of evidence rather than the evidence itself. For example, trust was explicitly placed in journals that were seen to have integrity:

\section{"... I read the editorial in the $B M J$ and it says it's OK. If Richard says it's OK then it is, it gets down to trust doesn't it? In the same way as the patients in general trust us to give them the most appropriate treatment ... [the $B M]$ ] has standing because you trust the people who edit it" (general practitioner 15).}

Hospital consultants were said to be among the most credible sources of evidence. The academic reputation and number of academic publications of a national specialist gave grounds for trust. The authority of local consultants was moderated by how they were perceived by individual doctors:

"Well I think I do have a sort of hierarchy within hospitals ... I've worked around Edinburgh so the consultant names mean something to me and ... I suppose I respect some more than I respect others ... and I would take[the opinions of] the ones that I value more highly with more importance" (general practitioner 17).

Respondents judged the trustworthiness of evidence on the basis of the perceived motives and interests of its source. Importantly, they had a clear perception of the economic interests which had fuelled the development of lipid lowering drugs and the evidence surrounding their use:

\footnotetext{
"There are a few theories knocking about. Some of them stand the test of time. Then drug companies market a new treatment" (general practitioner 3).
} 
The wider social and economic issues surrounding new treatments then trigger activity which gives further profile to the "trial evidence":

"Then the [local] prescribing adviser has been talking to us about it. The raised cost of statins and the need to prescribe cost effectively. You notice there is a groundswell of opinion" (general practitioner 12).

The credibility of sources was also judged according to their perceived economic self interest in this development. Thus, the local health board lacked credibility because of its cost containing agenda, and pharmaceutical representatives were distrusted because of the economic interest of their companies.

\section{Consensus and reinforcement}

Trust in a source of trial data is not by itself enough to transform these data into "practical knowledge." Clinical trial data become relevant for everyday practice only when they are confirmed and reiterated by other sources and underpinned by a clear consensus. The term "consensus" was used by several respondents and referred to the culmination of a gradual process by which they came to recognise agreement among significant sources of information. Respondents did not define "consensus" succinctly but they described the process leading to it in various ways-for example, "things are coming together, and becoming clearer"; "cumulative effect of various articles"; "it's all sort of slowly slipping into shape-pretty clear now what we have to do." We then used the term "consensus" analytically to describe the point at which "trial data" became practically relevant knowledge.

For all respondents except one reading or hearing about the Scandinavian study had not been enough to convince them that they should change their practice. Reinforcement from several sources had been needed. Written information had been supported by information from continuing education meetings, meetings with the prescribing adviser, and opinion of consultants in, for example, letters. Pharmaceutical representatives had fortified the consensus. Thus, however trustworthy sources of trial data are judged to be it is only when they buy into a consensus that what they say becomes "practical knowledge." One general practitioner explained why he trusted a consultant cardiologist who spoke at a meeting he attended, saying:

"What he said either made sense or backed up other sources of information that I might have had. He never said anything controversial I don't think or whatever. So he more or less supported what I think to be the general consensus" (general practitioner 20).

Interestingly, this view was parallelled by the way the local consultants whom we interviewed suggested that the impact of the Scandinavian study came partly from the fact that the findings were entirely expected. They crystallised knowledge, assumptions, and practice which already existed.

\section{Clinical guidelines}

Clinical guidelines were rarely seen as instrumental in the development of consensus but were seen as useful when they embodied and reinforced consensus. In part this reflects doubt about the provenance of guidelines and scepticism about the motives of people who develop them. Local guidelines produced by people known to the respondents were more widely used than national guidelines even when these were produced by people of acknowledged national and international repute. Guidelines from pharmaceutical companies were usually disregarded because their intentions were distrusted. Respondents rarely assessed the data or literature on which the guidelines were based.

Respondents referred to guidelines mainly in relation to biomedical aspects of their work. For example, local guidelines on the treatment of Helicobacter pylori in peptic ulcer disease were often mentioned as helpful in clarifying a confusing part of clinical practice.

\section{Normative process}

Once consensus was recognised a normative process operated whereby practitioners took steps to incorporate this consensus into their practice and avoid being seen to act outside the parameters of current best practice. Only two respondents were critical of the consensus regarding prescribing of statins in secondary prevention, and they had a strong alternative view of the needs of their patients and of their own role. The influence of the prescribing adviser was evident at this stage. Interviewees reported visits from the adviser to their practice and presentation of practice prescribing data compared with prescribing in the region overall. Generally, discovering practice prescribing to be atypical led to initiatives - for example, audit-to redress this.

\section{Discussion}

Although reports that $81 \%$ of interventions in general practice are evidence based imply general practitioners may practice evidence based medicine widely, ${ }^{18}$ our findings suggest they largely do so passively rather than actively. Our respondents were broadly aware of the trial evidence that exists for the treatment of hypercholesterolaemia and this had, in part, become integrated into their everyday practice. Although they admitted to a lack of technical skills to appraise the content of evidence produced by clinical trials, they critically and pragmatically evaluated conclusions of trials within wider contexts. Foremost among these were the economic factors impinging on primary care medicine and their personal attitudes to patient care determined in part by their own values and political perspectives.

Our respondents' interpretation was congruent with the literature of the sociology of science,${ }^{19}$ which states that data from scientific trials are the product of a social process and thus more subjective than is generally recognised in the debate about evidence based medicine. Our results suggest that trial data become integrated into everyday practice through a similar social process. "Experience based practice," sometimes criticised as idiosyncratic and subjective, is strongly influenced by a credible local consensus which is in turn more objective than is often recognised.

It is thus apparent that information from trials acquires its status as practical knowledge not because of the scientific rigour by which it is produced but only when it is underpinned by a clear and local consensus which takes account of the context in which the trial data are to be used. 
Key messages

- Use of clinical trial evidence to underpin everyday practice is seen as a key component of a cost effective high quality health service

- Strategies to facilitate use of clinical evidence in practice-for example, appraisal and clinical guidelines-may fail if they are based on unrealistic models of how evidence is assessed

- In this study the general practitioners interviewed rarely critically appraised trial data but evaluated trial evidence in terms of its social and economic implications

- Local consensus about trial findings and their implications strongly influenced incorporation of trial evidence into everyday practice

- Strategies to maximise the use of clinical evidence in practice should build on local consensus

\section{Practical implications}

These findings have implications for the strategies used to encourage general practitioners to base their practice on clinical evidence. Teaching general practitioners critical appraisal skills and developing guidelines may redress identified skill deficiencies and distil trial data in accessible form, but universal awareness and acceptance of trial findings alone may not lead to their integration into everyday practice.

Strategies to maximise evidence based practice may not work if they fail to recognise the judgments general practitioners already make about trial data and the process by which trial data become practically applicable. Our findings confirm that strategies are more likely to be effective if they recognise and build on developing informal consensus about trial data. Imminent organisational changes within the $\mathrm{NHS}^{12}$ provide the impetus to manage this process purposefully so that it links individual general practitioners' application of trial data to effective use of local resources, chiefly cash limited prescribing budgets, to meet local needs. This requires cooperation and negotiation among important local players-for instance, primary care groups ( local health care cooperatives in Scotland), primary and secondary care trusts, and local health authorities-so that this consensus is formalised and made transparent.
We thank all the participating general practitioners, consultants, and health board staff who generously gave of their time and knowledge, and Sally Wyke, senior research fellow for her support, advice, and theoretical input throughout the study.

Contributors: KF initiated the project. KF and GH designed the study, collected and analysed the data, and wrote the paper. $\mathrm{KF}$ and $\mathrm{GH}$ are joint guarantors of the work.

Funding: The project was funded by the Primary Care Research Fund, Chief Scientist's Office, Scottish Office.

Conflict of interest: None declared.

1 Secretary of State for Scotland, Scottish Office, Department of Health. Designed to care:renewing the National Health Service in Scotland. Edinburgh: Stationery Office, 1997.

2 Department of Health. The new NHS. London: Stationery Office, 1997. (Cm 3807.)

3 Rosenberg W, Donald A. Evidence based medicine: an approach to clinical problem solving. BMJ 1995;310:1122-6.

4 Sullivan FM, MacNaughton RJ. Evidence in consultations: interpreted and individualised. Lancet 1996;348:941-3.

5 McColl A, Smith H, White P, Field J. General practitioners' perceptions of the route to evidence based medicine: a questionnaire study. BMJ 1998;316:361-5

6 Armstrong D, Reyburn H, Jones R. A study of general practitioners' reasons for changing their prescribing behaviour. BMJ 1996;312:949-52.

7 Horder J, Bosanquet N, Stocking B. Ways of influencing the behaviour of general practitioners. J Roy Coll Gen Pract 1986;36:517-21.

8 Allery LA, Owen PA, Robling MR. Why general practitioners and consultants change their clinical practice. BMJ 1997;314:870-4.

9 Scandinavian Simvastatin Survival Group. Randomised controlled trial of cholesterol lowering in 4444 patients with coronary heart disease: the Scandinavian simvastatin survival study (4S). Lancet 1994;344:1383-9.

10 Shepherd J, Cobbe SM, Ford I, Isles C, Lorimer AR, MacFarlane PW, et al. Prevention of coronary heart disease with pravastatin in men with hypercholesterolemia. N Engl J Med 1995;333:1301-7.

11 Freemantle N, Barbour R, Johnson R, Marchment M, Kennedy A. The use of statins: a case of misleading priorities? BMJ 1997;315:826-7.

12 Caro J, Klittich W, McGuire A, Ford I, Norrie J, Pettitt D, et al. The West of Scotland coronary prevention study: economic benefit analysis of primary prevention with pravastatin. $B M J$ 1997;315:1577-82.

13 Standing Medical Advisory Committee. The use of statins. London: Department of Health, 1997. (11061D Aug 97(04).)

14 Maxwell M, Howie JGR, Pryde CJ. A comparison of three methods of setting prescribing budgets derived from DDD analyses of historic patterns of use. Br J Gen Pract 1998;48:1467-72.

15 Sacks FM, Pfefer MA, Moye LA, Rouleau JL, Rutherford JD, Cole TG, et al. The effect of pravastatin on coronary events after myocardial infarction in patients with average cholesterol. $N$ Engl $J$ Med 1996;335:1001-9.

16 Naylor CD. Grey zones of clinical practice: some limits of evidence based medicine. Lancet 1995;345:840-2.

17 Wyatt J. Use and sources of medical knowledge. Lancet 1991;338:1368-73.

18 Gill P, Dowell AC, Neal RD, Smith N, Heywood P, Wilson AE. Evidence based general practice: a retrospective study of interventions in one training practice. $B M J$ 1996;312:819-21.

19 Kuhn TS. The structure of scientific revolutions. 2nd ed. Chicago: University of Chicago Press, 1970.

(Accepted 17 September 1998)
Editorial by Fahey and pp 1120, 1125, 1130

continued over

BMJ 1998;317:1134-5
The first trial to show that patients with coronary heart disease treated with lipid lowering drugs gained a survival advantage was published in November 1994. ${ }^{1}$ Other similar trials that used hydroxymethyl glutaryl coenzyme A (HMG-CoA) reductase inhibitors, or statins, have subsequently confirmed these results (Longterm Intervention with Pravastatin in Ischaemic Disease (LIPID) Study Group, 70th scientific sessions of the American Heart Association, Florida, November 1997). ${ }^{2}$ Despite this, consistent failure occurs in the implementation of these findings. ${ }^{3}$ This study of primary care in South East Thames investigated variation between practices in the use of lipid lowering drugs and examined how prescribing has changed over time between different health authorities since 1990.

\section{Subjects, methods, and results}

Four health authorities were chosen to represent the range of demographic variables (including age, ethnic group, and social status) found in this region. These 